\title{
Judith Arnal*
}

\section{Fernando Hernández}

\author{
Ana Pajón*
}

Lucía Paternina*

\section{POLÍTICA FISCAL Y ESTABILIDAD FINANCIERA: LOS EFECTOS DE LOS AVALES PÚBLICOS EN RESPUESTA A LA CRISIS DE LA COVID-19}

Este artículo aborda los vínculos existentes entre la política fiscal y la política macroprudencial en un año en el que la interacción entre ambas ha resultado clave, enfocándose en los efectos que las medidas de política fiscal pueden tener sobre la estabilidad financiera. De este modo, además de exponer los principales vínculos desde un punto de vista teórico, se abordan las medidas monetarias, fiscales y macroprudenciales para hacer frente a la crisis sin precedentes que ha supuesto la pandemia ocasionada por la COVID-19. Se pone un acento especial en los esquemas de garantías públicas, analizando el impacto que las líneas de avales aprobadas por el Gobierno de España han tenido sobre la estabilidad financiera.

\section{Fiscal policy and financial stability in the COVID-19 era: The effects of Guarantee Schemes}

This article shows the existing links between the fiscal policy and the macroprudential policy, focusing on the effects that fiscal policies can have on financial stability, a topic that is particularly relevant at this juncture. In addition to show the main links between the two policies from a theoretical perspective, we review the monetary, fiscal and macroprudential measures implemented to face the economic crisis caused by the COVID-19. We also analyze the Guarantee Schemes approved by the Spanish Government and we study the impact that this public policy has had on financial stability.

Palabras clave: estabilidad financiera, deuda pública, política fiscal, marco institucional financiero, herramientas macroprudenciales, riesgos sistémicos, COVID-19.

Keywords: financial stability, public debt, fiscal policy, financial institutional framework, macroprudential tools, systemic risks, COVID-19.

JEL: E44, E60, G18, O16.

\footnotetext{
* Gabinete Técnico y de Análisis Financiero de la Secretaría General del Tesoro y Financiación Internacional.

Versión de enero de 2021.

https://doi.org/10.32796/ice.2021.918.7160
} 


\section{Introducción}

La política fiscal cumple tres funciones básicas en cualquier economía: asignación, redistribución y estabilización. A los efectos de este trabajo, interesa especialmente la vertiente estabilizadora de la política fiscal, que puede definirse como el conjunto de medidas empleadas por el Gobierno para estabilizar la economía mediante la gestión del nivel y la composición de impuestos y gasto público.

Por otro lado, se entiende por política macroprudencial aquella que usa instrumentos prudenciales para prevenir la acumulación de riesgos sistémicos. A su vez, se entiende por riesgo sistémico el riesgo de interrupción en la provisión de servicios financieros causado por deficiencias de una parte o de la totalidad del sistema financiero que puede tener un efecto importante en la actividad económica (IMF, FSB \& BIS, 2016).

Existe abundante literatura científica acerca de las interrelaciones entre la política monetaria y la política macroprudencial. Sin embargo, las contribuciones relativas a las interrelaciones entre las políticas macroprudencial y fiscal son notablemente más escasas ${ }^{1}$. En un contexto en el que las medidas fiscales de carácter discrecional han aumentado de manera muy relevante como respuesta a la crisis de la COVID-19, es importante seguir profundizando en este ámbito menos explorado de la literatura financiera.

Las políticas fiscal y macroprudencial se relacionan entre sí, produciendo efectos la una sobre la otra. Por un lado, si el sector público tiene que financiar niveles demasiado elevados de déficit público, puede llegar a poner en riesgo la estabilidad financiera, tal y como ocurrió durante la crisis del euro de 2010-2012 en países como Grecia y Chipre. En estos países mediterráneos, los elevados niveles de deuda pública fueron asumidos

\footnotetext{
1 Aun así, esta laguna en la literatura está comenzando a cubrirse. De hecho, al tiempo que se finalizaba este artículo se ha publicado la versión preliminar de un nuevo estudio por parte de José E. Boscá, Javier Ferri y Margarita Rubio sobre la relación entre política fiscal y macroprudencial en una Unión Monetaria (Boscá et al., 2020).
}

en gran parte por los bancos domésticos. Al aplicarse la quita de deuda pública a Grecia en el año 2012, los balances de estos bancos sufrieron un fuerte impacto.

Por otro lado, una política macroprudencial mal calibrada también puede llegar a generar problemas de estabilidad financiera que devengan en un incremento del gasto público y, por tanto, de las emisiones de deuda pública, con el consiguiente potencial aumento del coste de financiación del Estado. Este fue el caso de Irlanda, por ejemplo, donde la gestación de una fuerte burbuja inmobiliaria apoyada sobre una concesión excesiva de crédito dio lugar a una importante crisis bancaria, que acabó por arrastrar al soberano irlandés a la petición de un programa de asistencia financiera internacional.

Además, no hay que perder de vista que una política macroprudencial apropiada también tiene efectos positivos sobre el margen fiscal del sector público en situaciones de crisis, dado que evita los devastadores costes que una crisis financiera puede tener sobre la economía, dejando margen para la implementación de otras políticas estabilizadoras.

Por lo tanto, el estudio de los vínculos entre la política fiscal y la política macroprudencial, así como los canales a través de los que ambas políticas se interrelacionan, resulta de gran relevancia en la actualidad.

Este artículo combina una aproximación teórica y general a la interrelación entre estas dos políticas, con una más empírica y centrada en la actual crisis de la COVID-19, desentrañando el impacto que las líneas de avales han tenido sobre la estabilidad financiera. De manera más específica, el segundo apartado de este artículo lleva a cabo un análisis de los principales canales de interrelación entre estas políticas, especialmente sobre la base de la literatura existente al respecto en la actualidad. El tercer apartado describe las principales respuestas de política económica que se han producido por los países europeos, especialmente por España, a la crisis de la COVID-19. El cuarto apartado pone el acento sobre las líneas de avales públicos, llevando a cabo una comparativa con el resto de la zona euro. Finalmente, el quinto apartado explora el impacto que 
las líneas de avales han tenido en términos de estabilidad financiera, concluyendo que este ha sido positivo.

\section{Vínculos entre la política macroprudencial y la política fiscal}

La forma de financiación del Estado de su déficit presupuestario es uno de los principales canales a través del cual ambas políticas se interrelacionan. La percepción de los agentes de la prudencia de la política fiscal condiciona la estabilidad financiera de un país, pudiendo, si esta se percibe como prudente, disminuir los riesgos sistémicos e incrementar la resiliencia de la economía ante shocks (Dumičić, 2019). Por lo tanto, a sensu contrario, una política fiscal insostenible tendrá un efecto negativo sobre la estabilidad financiera, que debería ser compensado con una política macroprudencial restrictiva.

Esto ofrece una primera conclusión referente a los vínculos entre ambas políticas: reaccionan de manera inversa ante cambios en el tono y orientación de la otra política.

No obstante lo anterior, la política macroprudencial será siempre más efectiva en prevenir una crisis financiera que en paliarla, una vez esta se ha iniciado ya. A modo de ejemplo, se puede pensar en las principales herramientas macroprudenciales del sector bancario. Herramientas como los límites a la concentración sectorial, la fijación de condiciones sobre la concesión de préstamos o la aplicación de mayores ponderaciones de riesgo a determinado tipo de exposiciones están especialmente orientadas a la prevención de burbujas crediticias o de prácticas de concesión de crédito irresponsables. Por tanto, se trata de herramientas fundamentalmente de naturaleza preventiva, que una vez desatada una crisis financiera, pueden no resultar tan efectivas. Por otro lado, el colchón de capital anticíclico, en caso de haberse acumulado en el pasado, sí podría llegar a generar efectos positivos en una situación de crisis financiera, aunque dependiendo de la magnitud de esta, podría llegar a resultar insuficiente.
De esta manera, se llega a una segunda conclusión: la política macroprudencial produce efectos asimétricos, siendo más efectiva en la prevención que en la resolución de crisis financieras.

Un segundo vínculo se da a través del canal del crédito al sector privado. Por un lado, dado que el tipo de interés al sector privado suele calcularse como un diferencial sobre los costes del sector público, en el caso de que una política fiscal expansiva incremente el tipo del interés al que se financia el sector público, se incrementarían los costes para el sector privado. Por otro lado, el efecto de una política macroprudencial que tienda a favorecer la tenencia de activos libres de riesgo por parte de las entidades financieras también reducirá en principio la concesión de crédito a la economía, dado que se producirá un efecto crowding out sobre el préstamo privado.

A partir de los vínculos a través del canal del crédito, puede extraerse una tercera conclusión: la necesidad de que la política fiscal y la política macroprudencial estén coordinadas.

El tercer canal viene dado por la prevención del riesgo moral. Los bancos están claramente afectados por riesgo moral, ya que preferirían sustituir inversiones en activos seguros $y$, por tanto, menos rentables, por otras más arriesgadas y rentables, esperando ser rescatados en el caso de que acontezca una crisis financiera. Sin embargo, una política macroprudencial tradicional establecería las medidas adecuadas para que los bancos inviertan en los activos más adecuados. En el caso de que no exista una crisis financiera, la política macroprudencial tendrá un efecto restrictivo, suponiendo una reducción en términos relativos del acceso del sector privado al crédito. Sin embargo, si se produce una crisis financiera, la política macroprudencial tendrá un efecto positivo al ahorrar los costes fiscales que supondría el rescate de los bancos (Reis, 2020).

Este último canal lleva a una cuarta conclusión: contar con una política macroprudencial orientada a la prevención de crisis financieras y la promoción de la estabilidad financiera conlleva ciertos costes en épocas de expansión económica. De este modo, una 
política macroprudencial estricta en situaciones de crisis resulta muy estabilizadora, al evitarse los elevados costes de crisis financieras, disponiendo el sector público de mayor margen fiscal para favorecer la estabilización de la economía. No obstante, en periodos de expansión que no vayan seguidos de una fuerte crisis financiera, la política macroprudencial puede generar ciertos costes en términos de expansión económica. Sin embargo, el impacto sobre la economía de una crisis financiera puede llegar a ser tan devastador que resulta conveniente asumir e internalizar esos costes.

En definitiva, las claras interrelaciones entre las políticas fiscal y macroprudencial apuntan en la dirección de que las políticas de demanda tradicionales deberían incorporar como objetivo no solo el empleo o la inflación, sino también el favorecimiento de la estabilidad financiera (Dumičić, 2019), evitando que se produzcan restricciones de crédito. Los costes de no considerar tal interrelación pueden ser tanto directos (por ejemplo, recapitalización de bancos, ejecución de garantías estatales) como indirectos (por ejemplo, recesiones más prolongadas, insostenibilidad de la deuda pública). La literatura ha tratado de estimar los costes de los episodios de crisis bancarias, que se sitúan entre el $2 \%$ del PIB y el $57 \%$ en el caso de crisis extremas, como la crisis argentina entre 1980 y 1982 o la Indonesia entre 1997 y 2001 (Laeven \& Valencia, 2012).

\section{Medidas económicas adoptadas para hacer frente a la COVID-19}

Para hacer frente a los efectos económicos de la crisis sin precedentes que ha supuesto la COVID-19, se han tomado una serie de medidas a nivel europeo y nacional, que han abarcado los frentes monetario, prudencial y fiscal.

\section{Medidas monetarias}

El Banco Central Europeo adoptó una serie de medidas de política monetaria encaminadas a mantener unas condiciones de financiación acomodaticias entre las que resaltan: el aumento de los límites del programa de compra de activos, Asset Purchase Programme, el programa de compras de emergencia frente a la pandemia, Pandemic Emergency Purchase Program, la mejora de los términos y las condiciones de las operaciones de financiación a largo plazo con objetivo específico (TLTRO III), el nuevo programa de operaciones de refinanciación a largo plazo de emergencia no orientadas (PELTRO) y la flexibilización de los requisitos de colateral. Estas medidas han llevado al balance del Banco Central Europeo a máximos históricos, tal y como se aprecia en la Figura 1.

\section{Medidas prudenciales}

Las autoridades prudenciales han liberado capital bancario para absorber pérdidas y apoyar el flujo de crédito a la economía real mediante la liberación de colchones de capital, orientaciones para reducir el aprovisionamiento procíclico y la restricción de las distribuciones de dividendos.

A la luz de algunas medidas tomadas frente a la COVID-19 (moratorias públicas y privadas), la Autoridad Bancaria Europea (ABE) emitió una declaración acerca de la aplicación del marco prudencial con el objetivo de proporcionar claridad al sector bancario de la UE sobre cómo tratar de manera consistente aspectos relacionados con la clasificación de préstamos en mora, la identificación de los préstamos renegociados o reestructurados y el tratamiento contable (IFRS 9). Además, más tarde, publicó unas directrices sobre el tratamiento de los préstamos sujetos a moratoria que cumplían determinadas características de elegibilidad, evitando así la reclasificación de numerosas operaciones como dudosas. Por su parte, el Comité de Supervisión Bancaria de Basilea permitió aplicar la ponderación de riesgo soberano a las operaciones con aval público y no tratar los préstamos con moratorias como reestructurados o refinanciados.

Por otra parte, las autoridades europeas llevaron a cabo una revisión de la normativa bancaria de los 


\section{FIGURA 1}

EVOLUCIÓN DEL BALANCE DEL BCE, POR COMPONENTES, SEMANAL, 2008-2020

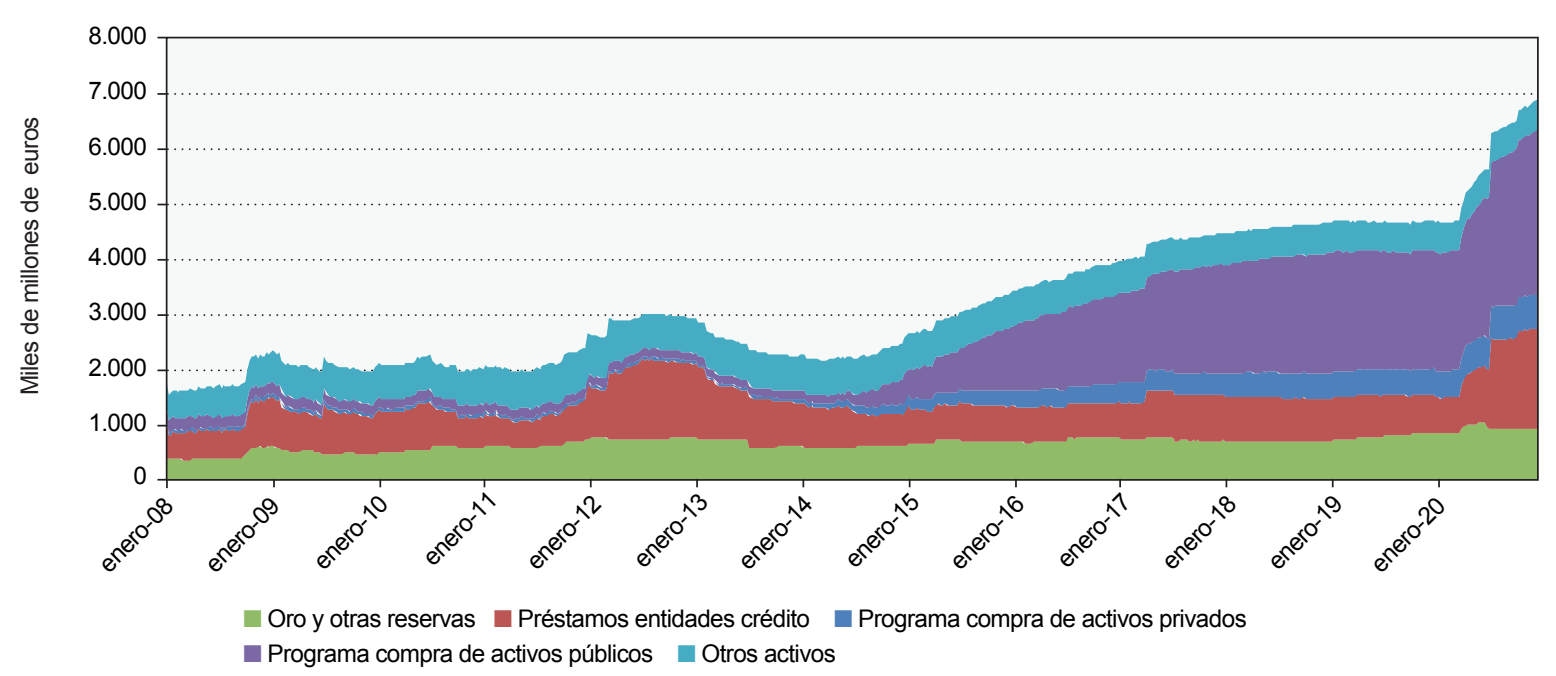

FUENTE: Bloomberg.

requerimientos de capital, conocido como el quick fix del Reglamento de Requisitos de Capital (CRR, por sus siglas en inglés), que supuso la introducción de un filtro prudencial para paliar cambios repentinos en el valor razonable de los activos financieros, mejoras en el tratamiento del uso de las facilidades de liquidez en el cálculo de la ratio de apalancamiento, tratamiento favorable para las exposiciones con garantía pública, ajustes de los requerimientos de riesgo de mercado y revisión del tratamiento transitorio de las provisiones por pérdidas esperadas.

El Mecanismo Único de Supervisión ha permitido temporalmente que las entidades bancarias operen por debajo de los niveles de capital y liquidez exigidos en el Pilar 2. A estas medidas, se suma la recomendación del BCE de no distribuir dividendos y de no recomprar acciones para la remuneración de los accionistas.

Por último, el Banco de España decidió mantener el colchón de capital anticíclico en el $0 \%$, mientras que otras autoridades europeas redujeron sus colchones.
Por su parte, la Comisión Nacional del Mercado de Valores (CNMV), en coordinación con la Autoridad Europea de Valores y Mercados (ESMA, por sus siglas en inglés), prohibió realizar ventas en corto con valores en los mercados españoles desde el 17 de marzo hasta el 19 de mayo. Por último, cabe mencionar la introducción de una nueva herramienta macroprudencial para la CNMV, si bien no llegó a activarse, relacionada con la posibilidad de establecer plazos de preaviso para los reembolsos sin sujeción a los requisitos de plazo, importe mínimo y constancia previa en el reglamento de gestión.

\section{Medidas fiscales}

En el plano fiscal, la mayoría de países se han visto obligados a aprobar medidas excepcionales para hacer frente a la pandemia y tratar de aliviar la carga que ha supuesto para hogares, autónomos y empresas. En la Unión Europea, esto ha sido en gran parte posible 


\begin{tabular}{|c|c|c|c|c|}
\hline CUANTIFI & $\begin{array}{l}\text { AS MEDIDAS FISC } \\
\text { E } 2019 \text { EN RESPU }\end{array}$ & $\begin{array}{l}\text { ABLA } 1 \\
\text { ES DISCR } \\
\text { TA A LA CF } \\
\text { En \%) }\end{array}$ & $\begin{array}{l}\text { IONALES COI } \\
\text { S DE LA COV }\end{array}$ & $\begin{array}{l}\text { PORCENTAJE DEL } \\
-19\end{array}$ \\
\hline País & Impulso fiscal inmediato & Diferimientos & Liquidez/garantías & Fecha de actualización \\
\hline Alemania & 8,3 & 7,3 & 24,3 & 04/08/2020 \\
\hline Francia & 5,1 & 8,7 & 14,2 & $05 / 11 / 2020$ \\
\hline Italia & 3,4 & 13,2 & 32,1 & $22 / 06 / 2020$ \\
\hline España & 4,3 & 0,4 & 12,2 & 18/11/2020 \\
\hline Países Bajos & 3,7 & 7,9 & 3,4 & $27 / 05 / 2020$ \\
\hline Bélgica & 1,4 & 4,8 & 21,9 & $22 / 10 / 2020$ \\
\hline Portugal & 2,5 & 11,1 & 5,5 & $04 / 05 / 2020$ \\
\hline Grecia & 3,1 & 1,2 & 2,1 & 05/06/2020 \\
\hline FUENTE: Bru & & & & \\
\hline
\end{tabular}

gracias al Marco Temporal de Ayudas de Estado aprobado por la Comisión Europea en marzo (y que sufrió posteriores modificaciones para ampliar la cobertura del mismo), así como a la activación de la cláusula de escape contenida en el Pacto de Estabilidad y Crecimiento.

La Tabla 1 muestra la estimación del centro de investigación Bruegel de las medidas fiscales discrecionales adoptadas en los principales países de la zona euro en respuesta a la COVID-19 como porcentaje del PIB de 2019.

En el caso concreto de España, dentro de las medidas fiscales pueden distinguirse según su objetivo:

- Las orientadas a reforzar el sistema sanitario, como por ejemplo, la reducción del IVA en la provisión de material sanitario a hospitales, nuevos fondos para investigación, entre otras.

- Aquellas cuya finalidad tiene que ver con la protección de empleo y las ayudas a los desempleados: los Expedientes de Regulación Temporal de Empleo (ERTE), la extensión de la prestación por desempleo a más colectivos y la mayor protección a desempleados con trabajos estacionales.
- Las medidas de apoyo a hogares y a empresas. En el caso de los hogares, se han concretado en moratorias bancarias en hipotecas, alquileres y préstamos, garantía de provisión de suministros esenciales e ingreso mínimo vital. Respecto a las medidas de apoyo a la liquidez y a la solvencia empresarial, encontramos las moratorias tributarias, las moratorias para el ingreso de las cuotas de la Seguridad Social, los aplazamientos en el pago de alquileres y suministros, las moratorias bancarias, las líneas de avales públicos (detalladas en el siguiente párrafo), el Fondo de Apoyo a la Solvencia de Empresas Estratégicas dotado con 10.000 millones de euros para otorgar apoyo financiero público temporal mediante la concesión de préstamos participativos, deuda subordinada, suscripción de acciones $\mathrm{u}$ otros instrumentos de capital, y los programas específicos de ayuda para algunos sectores (como el turístico, con una línea de financiación del Instituto de Crédito Oficial, ICO, de 400 millones de euros).

Entre las medidas fiscales orientadas a la preservación del acceso de empresas y autónomos al crédito $y$, por tanto, de la estabilidad financiera, destacan de manera muy relevante las líneas de avales, en su gran 
mayoría canalizadas a través del ICO. En el siguiente apartado, se lleva a cabo un repaso de esta iniciativa, que ha sido empleada también de manera masiva en otros países de la Unión Europea.

\section{Los avales públicos en el contexto de la crisis de la COVID-19}

El estallido de la crisis sanitaria de la COVID-19, con las medidas de restricción de movimientos que las autoridades públicas se han visto obligadas a adoptar, ha generado importantes retos para la actividad económica. Sin lugar a dudas, uno de esos retos consiste en la cobertura de las necesidades de liquidez de las empresas no financieras y autónomos. La teoría económica convencional dicta la conveniencia de adoptar políticas fiscales contracíclicas. Ello pasa por tomar medidas expansivas en épocas de recesión económica. En este sentido, ante las crecientes necesidades de liquidez que iban a experimentar las empresas y autónomos y la posible inapetencia por facilitar el acceso al crédito de las entidades financieras, debido a un deseo de mitigación de riesgos, varios países de la Unión Europea, entre ellos España, optaron por la concesión de avales públicos a la financiación. Ello se ha visto facilitado por la aprobación por parte de la Comisión Europea del Marco Temporal de Ayudas de Estado, que ha supuesto una flexibilización de las normas tradicionales de ayudas de Estado, en atención a las muy especiales circunstancias económicas en que se encuentra la economía mundial en general y la europea en particular.

La figura del aval público supone un uso eficiente de los recursos públicos, en la medida en que se trata de un pasivo contingente. Así, no se registrará impacto alguno ni en déficit ni en deuda públicos hasta que no se haya registrado un impago. En la medida en que la crisis de la COVID-19 está llamada a ser temporal, la previsible recuperación del tejido productivo permitirá que la mayor parte de las empresas y los autónomos atiendan sus obligaciones de pago, produciéndose un impacto menor sobre las cuentas públicas.
El pasado marzo se aprobó en España una línea de avales otorgada por el Ministerio de Asuntos Económicos y Transformación Digital para cubrir la financiación otorgada por entidades de crédito, establecimientos financieros de crédito, entidades de dinero electrónico y entidades de pagos a empresas y autónomos. El objetivo fundamental de esta línea de avales, dotada con un importe máximo de 100.000 millones de euros, era preservar la normalidad de los flujos de financiación y de los niveles de circulante y liquidez. En julio se decidió una nueva línea de avales dotada con 40.000 millones de euros para los préstamos para la realización de nuevas inversiones, así como los gastos relacionados con las mismas y con la mejora del proceso productivo. En ambas líneas la activación se produce por tramos, el ICO se encarga mayoritariamente de su gestión y el aval garantiza el $80 \%$ de las nuevas operaciones de autónomos y pymes y el $70 \%$ de los nuevos préstamos solicitados por el resto de empresas.

Como hemos indicado más arriba, la decisión de España de introducir líneas de avales no ha sido aislada, sino que se ha registrado en una amplia mayoría de países de la zona euro. En la Tabla 2, se recoge un breve resumen de las principales características publicadas por la Autoridad Bancaria Europea de los esquemas de garantías de varios países de la zona euro.

Además de los elementos diferenciales recogidos en la Tabla 2, destaca el distinto importe de los programas de avales aprobados en los principales países de la zona euro. Así, los importes de los esquemas aprobados por Alemania, Francia e Italia son superiores al español, tanto en términos absolutos como en relación al PIB de cada economía. Destaca especialmente el alemán, que se sitúa en casi el $22 \%$ del PIB, seguido por el italiano (17\%) y el francés (12\%). EI español supone un $11 \%$ del PIB. Sin embargo, el uso que han tenido los avales públicos ha sido heterogéneo entre los países. En términos absolutos la utilización en Francia y España es muy superior a la de Italia y Alemania (Figura 2). Como porcentaje de utilización 


\section{TABLA 2}

\section{CARACTERÍSTICAS DE LOS ESQUEMAS DE AVALES APROBADOS POR DISTINTOS PAÍSES DE LA ZONA EURO}

\begin{tabular}{|c|c|c|}
\hline País & Autoridad garante & Exposiciones cubiertas \\
\hline Alemania & Kreditanstalt für Wiederaufbau & $\begin{array}{l}\text { Nuevos préstamos a empresas no } \\
\text { financieras. }\end{array}$ \\
\hline Francia & Gobierno de Francia & $\begin{array}{l}\text { Nuevos préstamos a empresas no } \\
\text { financieras viables. }\end{array}$ \\
\hline Italia & $\begin{array}{l}\text { SACE como garante y el Gobierno } \\
\text { de Italia como contragarante }\end{array}$ & $\begin{array}{l}\text { Nuevos préstamos a empresas no } \\
\text { financieras viables. }\end{array}$ \\
\hline España & $\begin{array}{l}\text { Ministerio de Asuntos } \\
\text { Económicos y Transformación } \\
\text { Digital }\end{array}$ & $\begin{array}{l}\text { Nuevos préstamos a autónomos y } \\
\text { empresas no financieras viables, } \\
\text { incluyendo las empresas públicas. } \\
\text { Solo se contemplará la posibilidad de } \\
\text { avalar líneas de crédito existentes en } \\
\text { los casos en que haya una ampliación } \\
\text { del plazo o un aumento de la cantidad. }\end{array}$ \\
\hline
\end{tabular}

Países Gobierno de Países Bajos

Nuevos préstamos a empresas de cualquier tamaño y programa especial para empresas del sector agrícola.

Para empresas del sector agrícola, $70 \%$ con una exposición máxima de 1,5 millones de euros. Para empresas de gran tamaño, $80 \%$ y para pymes $90 \%$, con una exposición máxima de 150 millones de euros. Para microempresas, $95 \%$, con una exposición máxima de 50.000 euros.

Nuevos préstamos a empresas no financieras viables.

La cobertura no se aplica por exposición, sino por carteras. Los bancos asumirán el primer $3 \%$ de las pérdidas de una cartera. Para pérdidas entre el 3 y el $5 \%$, el Estado asumirá el $80 \%$ de las pérdidas y el banco el $20 \% .10 .000$ millones de euros.

$90 \%$ para microempresas y pequeñas empresas. $80 \%$ para empresas medianas. necesidad de capital circulante. Se excluyen las operaciones de refinanciación, así como los nuevos préstamos para la adquisición de bienes inmuebles o vehículos no destinados al uso profesional. Las empresas han de cumplir una serie de condiciones financieras (por ejemplo, tener resultados positivos netos en el último balance).

Nuevos préstamos a empresas no financieras, excluyendo las empresas del sector público y las del sector armamentístico.
$80 \%$, siempre y cuando las pérdidas del conjunto de la cartera de la entidad financiera no supere el $40 \%$ para pymes y el $30 \%$ para grandes empresas.

FUENTE: Autoridad Bancaria Europea. 


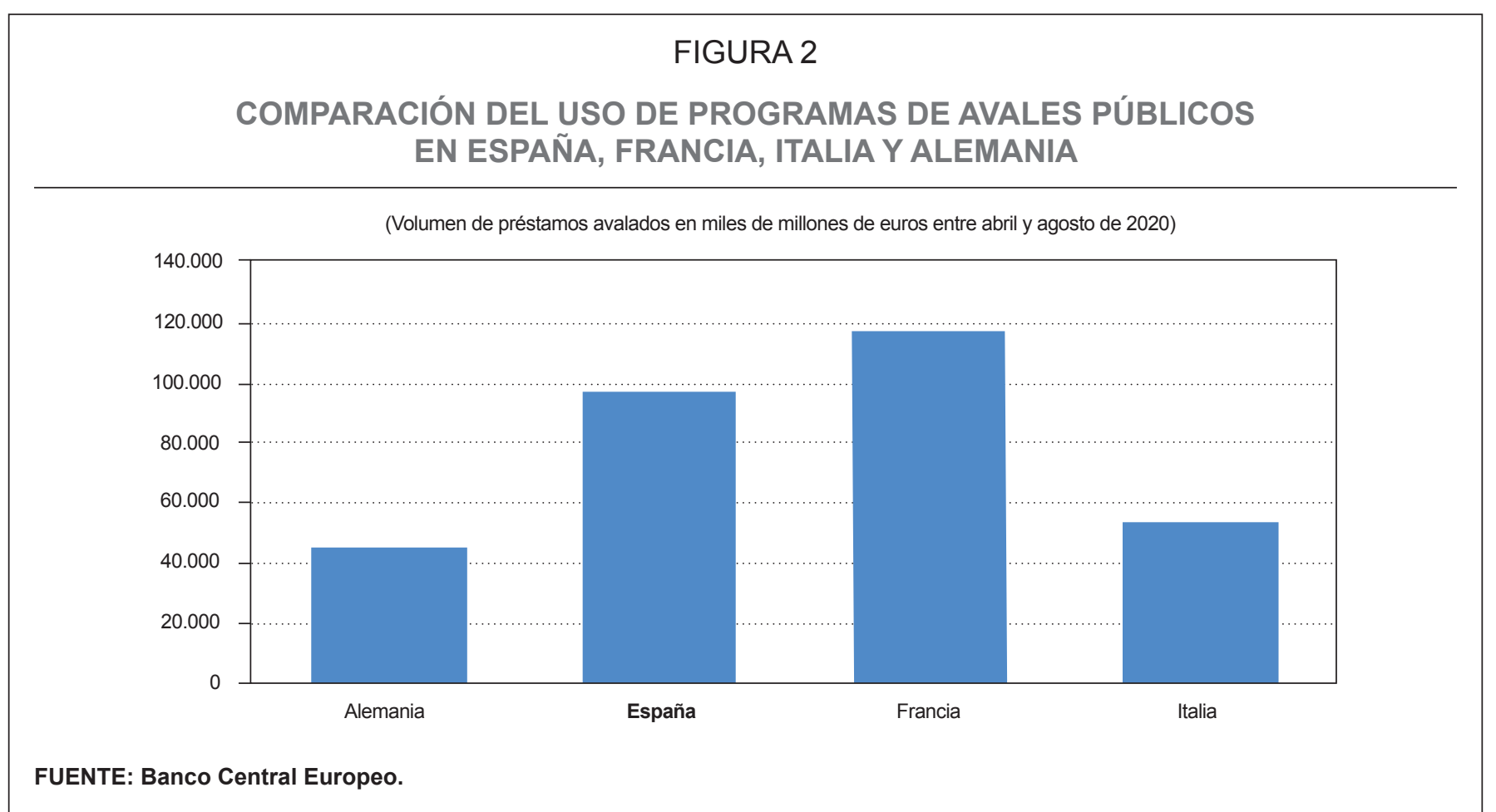

sobre el total del programa aprobado destaca significativamente España sobre Francia e Italia, y sobre todo, respecto a Alemania. Además, si tenemos en cuenta el peso de los avales en el nuevo crédito bancario total, el impacto es más significativo también en España.

Por otra parte, si nos fijamos en la evolución temporal de los préstamos avalados, abril fue el mes en el que más préstamos avalados se concedieron en España y Francia y después han ido decreciendo progresivamente. En Italia, por el contrario, en abril no se concedieron préstamos avalados, sino que comenzaron en mayo, se incrementaron en junio y se han mantenido en un volumen superior al de Francia y España desde entonces. Esta evolución es un reflejo de la rapidez y eficiencia operativa del programa de avales desplegado en Francia y España frente a los cuellos de botella operacionales que existieron en Italia los primeros meses.

Una vez explicadas la importancia de las líneas de avales como respuesta a la crisis de la COVID-19 y las distintas características entre Estados miembros de la zona euro, conviene pasar a centrarse en el caso español, con el fin de estimar el impacto de esta medida de política económica sobre la estabilidad financiera.

5. ¿Cómo afectan las líneas de avales a la estabilidad financiera?

Con el fin de analizar el impacto de las líneas de avales sobre la estabilidad financiera, se analizan tres aspectos: i) impacto sobre la evolución del crédito en España; ii) impacto sobre las condiciones de los préstamos concedidos en España; iii) impacto sobre los balances bancarios; y iv) posibles riesgos.

\section{Impacto de los avales públicos en la evolución del crédito en España}

El nuevo crédito a sociedades no financieras creció fuertemente en términos interanuales en los meses 
FIGURA 3

\section{EVOLUCIÓN DEL NUEVO CRÉDITO A SOCIEDADES NO FINANCIERAS}

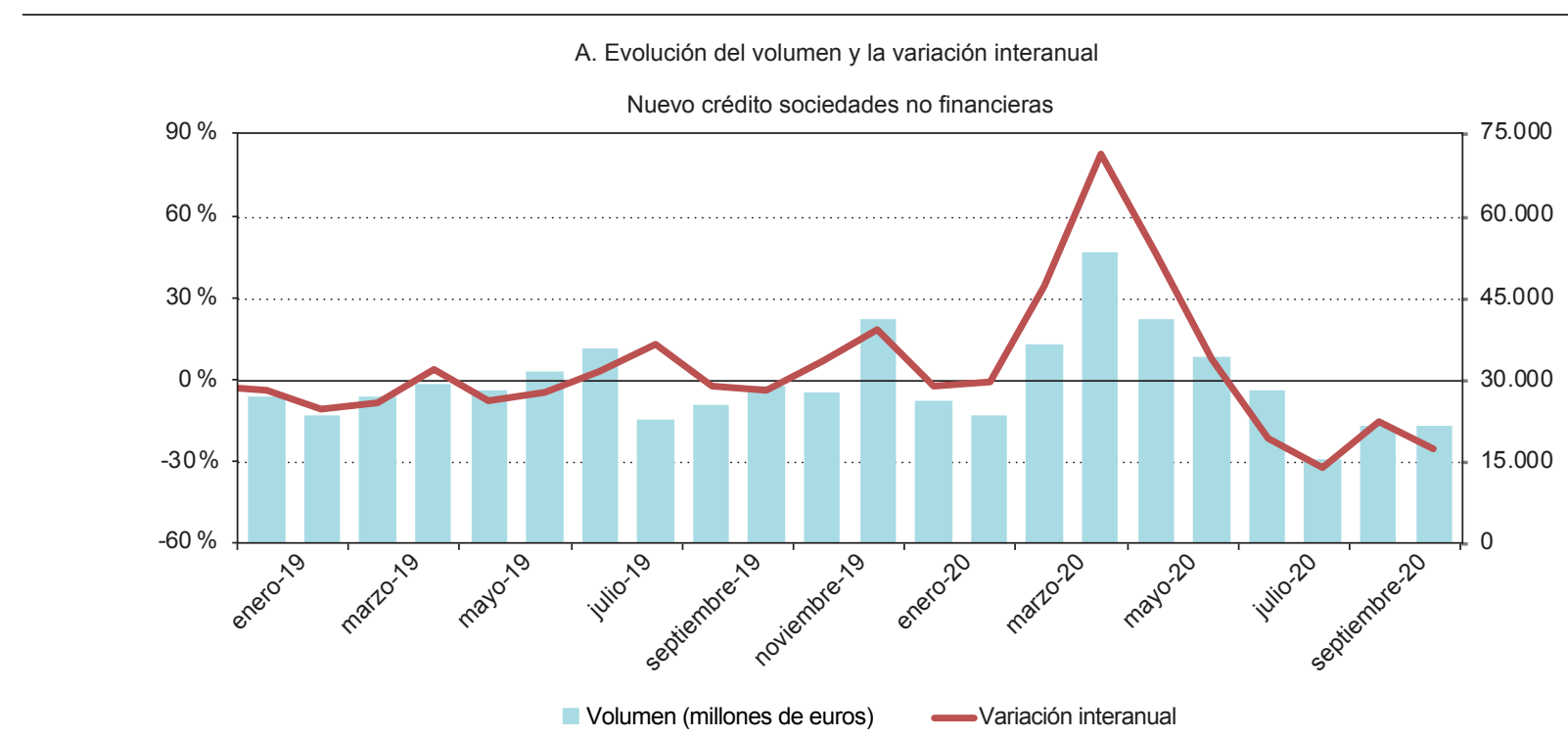

B. Evolución de las operaciones nuevas del programa ICO

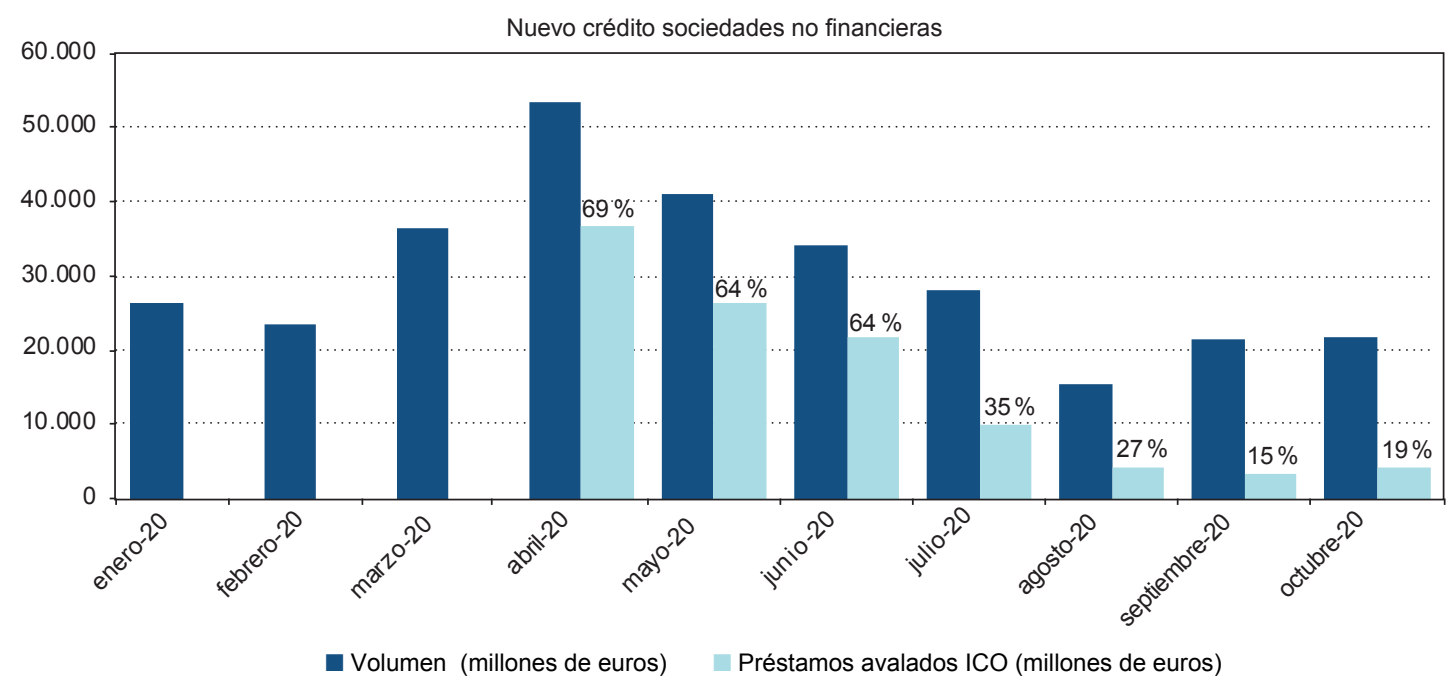

FUENTE: Banco de España e ICO.

de marzo, abril, mayo y junio (Figura 3). Este crecimiento fue especialmente destacable en abril, alcanzando el $82,8 \%$ y se fue suavizando en los meses de mayo $(+46,9 \%)$ y junio $(+8,1 \%)$. Esta tendencia se ha revertido a partir del mes de julio, con crecimientos interanuales negativos durante cuatro meses consecutivos: julio $(-21,3 \%)$, agosto $(-32,3 \%)$, septiembre $(-15,1 \%)$ y octubre $(-25,1 \%)$. 


\section{FIGURA 4}

\section{FINANCIACIÓN SEGÚN EL NOMINAL DEL PRÉSTAMO}

A. Financiación bancaria total

Financiación (millones de euros) según nominal del préstamo

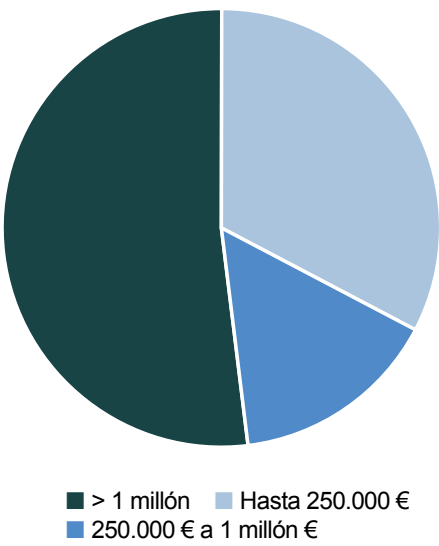

B. Financiación avalada por el ICO

Financiación (millones de euros) según nominal del préstamo

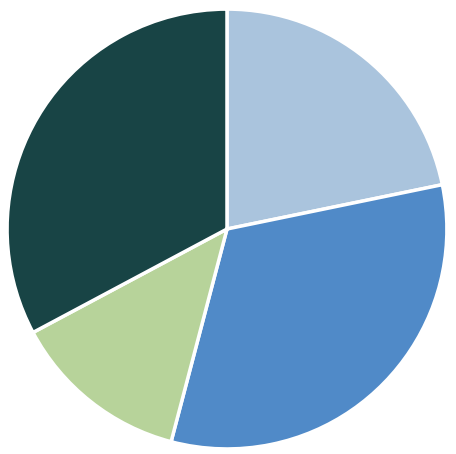

Hasta $100.000 € \quad 100.000$ a $500.000 €$

500.000 a 1 millón $€$ Más de 1 millón $€$

FUENTE: Banco de España e ICO.

En abril, casi el $70 \%$ de los préstamos bancarios nuevos fueron otorgados a través del programa de avales públicos del ICO. En los meses siguientes ha aumentado el peso de las nuevas operaciones de crédito otorgadas fuera del programa de avales.

Por lo tanto, los avales ICO fueron claves para hacer frente a las necesidades de liquidez de las empresas, que se agudizaron en los meses de marzo a mayo como consecuencia de las medidas implementadas para luchar contra la expansión de la COVID-19. Estas medidas supusieron la reducción de los ingresos de las empresas, debido a la práctica paralización de la actividad económica y la caída de la demanda. Por ello, muchas empresas decidieron recurrir al crédito bancario que aumentó fuertemente. Como hemos visto, las operaciones ICO explican gran parte del aumento de las nuevas operaciones de crédito.

Además, el crédito a través de avales ICO se ha concentrado fundamentalmente en pymes y autónomos (98 \% del total de operaciones realizadas), representando un $70 \%$ del total del crédito canalizado a través de las líneas ICO. Las operaciones a no pymes son mucho menores en número, pero con una financiación media por operación de casi 2 millones de euros, muy superior a la financiación media de las operaciones de pymes, que se sitúa en torno a los 215.000 euros, de micropymes, que prácticamente alcanza los 58.000 euros y sobre todo de autónomos, que se sitúan en los 27.000 euros. La mayor utilización de las líneas de avales por parte de pymes y autónomos se explica, por un lado, porque los tramos destinados a ellas tienen un mayor importe agregado, 67.500 millones de euros frente a 25.000 millones de euros destinados a las no pymes. Sin embargo, este mayor uso también se debe a que precisamente son las pymes y autónomos los que peores condiciones de acceso al crédito tienen.

El Banco de España no publica estadísticas sobre crédito en función del tamaño de la empresa. Podemos basarnos como proxy en el nominal de los préstamos para hacer una comparativa entre la financiación 
bancaria total y la avalada. Atendiendo a la Figura 4, podemos observar cómo la financiación avalada por el ICO se concentra en importes nominales menores mientras que en la financiación bancaria total, los préstamos de mayor importe, por encima de un millón de euros, adquieren más peso. Esto se explica porque los préstamos avalados por el ICO se han concentrado en pymes y autónomos que solicitan menores importes nominales.

La concentración del crédito avalado por el ICO en las empresas con peores condiciones de acceso al crédito se muestra también en la distribución sectorial. De esta forma, se puede observar que el crédito avalado por la línea ICO se ha concentrado en los sectores que más se han visto afectados por la crisis. En concreto, los sectores de turismo, ocio y cultura, acaparan un $15 \%$ de la financiación, en primera posición por delante del sector de la construcción e infraestructuras que supone un $11 \%$ del total.

En definitiva, los avales canalizados a través del ICO han permitido garantizar el acceso al crédito en los meses de confinamiento más duro, como atestigua la evolución del crédito interanual entre los meses de marzo y junio. Además, los préstamos avalados han sido principalmente absorbidos por pymes y autónomos, principales componentes del tejido empresarial español. De hecho, si se compara con el crédito no avalado, el nominal del préstamo avalado es inferior, lo que puede ser un indicativo de que va más dirigido a negocios de pequeño tamaño que los préstamos tradicionales no avalados. Por último, los créditos avalados se concentran especialmente en empresas de sectores que tienen peores condiciones de acceso al crédito (por ejemplo, turismo, ocio y cultura), lo que da una idea también del papel amortiguador de la crisis que han jugado las líneas de avales.

\section{Impacto de los avales públicos en las condiciones de los préstamos concedidos}

Resulta interesante comparar no solo la evolución y distribución de la financiación avalada respecto al total de la financiación bancaria, sino también las condiciones en las que se han concedido una y otra. En este sentido podemos atender a los plazos y a los tipos de interés a los que se han concedido los préstamos.

En relación con los plazos, en primer lugar, hay que tener en cuenta que la línea de avales ICO contaba con un límite superior en el momento de la concesión de 5 años. Recientemente, se ha levantado esta limitación, situando el límite en 8 años para los nuevos avales y permitiendo extensiones del plazo de vencimiento de los avales ya otorgados en 3 años, siempre y cuando el vencimiento total del préstamo no supere los 8 años. En el momento de redacción de este artículo, todavía no ha comenzado el plazo para la solicitud de las extensiones, por lo que no es posible conocer qué uso tendrán.

De esta forma, como se observa en la Tabla 3, los préstamos con avales ICO se han concentrado en el máximo plazo permitido, entre 4 y 5 años. Sorprendentemente, los préstamos a 3 y 4 años han sido poco solicitados, mientras que los préstamos con vencimiento entre 2 y 3 años son la segunda categoría de más solicitud. Los préstamos a corto plazo, de menos de 1 año y hasta 2 años, son los menos utilizados.

Esta distribución por plazo de vencimiento, con mayor concentración en el largo plazo, es opuesta a la del resto de financiación bancaria. Así entre marzo y octubre de 2020 , el $71 \%$ de los préstamos concedidos fueron a menos de un año. Si además analizamos la evolución de los préstamos en función de su plazo mes a mes, podemos observar que en abril y mayo, meses en los que destaca el peso de los avales en el volumen total de financiación, el porcentaje de préstamos totales con vencimiento hasta un año es inferior (48 \% y $54 \%$ respectivamente), mientras que en agosto, septiembre y octubre, meses en los que los préstamos avalados tienen un menor peso sobre el total de la financiación, los préstamos totales con vencimiento hasta un año suben hasta en torno al $85 \%$ del total. Por lo tanto, los préstamos avalados por el ICO han estado mucho más sesgados hacia el largo plazo que el resto de la financiación bancaria.

Respecto a los tipos de interés, los préstamos avalados por el ICO han contribuido a mejorar las 


\begin{tabular}{|c|c|c|}
\hline \multicolumn{3}{|c|}{ TABLA 3} \\
\hline \multicolumn{3}{|c|}{$\begin{array}{c}\text { NUEVOS CRÉDITOS TOTALES Y AVALADOS POR PLAZO DE VENCIMIENTO EN EL PERIODO } \\
\text { DE MARZO A OCTUBRE DE } 2020 \\
\text { (En \%) }\end{array}$} \\
\hline Plazo del préstamo & Préstamos avalados & Préstamos totales \\
\hline Hasta 1 año & 3 & 71 \\
\hline Entre 1 y 2 años & 3 & \multirow{4}{*}{21} \\
\hline Entre 2 y 3 años & 31 & \\
\hline Entre 3 y 4 años & 3 & \\
\hline Entre 4 y 5 años & 60 & \\
\hline Más de 5 años & 0 & 8 \\
\hline
\end{tabular}

condiciones, especialmente para aquellos deudores que normalmente tienen más dificultades para acceder al crédito, produciéndose un traspaso efectivo de la ayuda estatal hacia el beneficiario final, es decir, las empresas. Para comprobar esto, nos basamos en la evolución de los tipos de interés de los nuevos créditos por importe nominal inferior a 1 millón de euros.

En la Figura 5, podemos observar que la TAE media de estos créditos en el periodo previo a la irrupción de la COVID, entre octubre de 2019 y febrero de 2020 era del $2,7 \%$, cifra muy superior a la TAE media ponderada de los préstamos ICO del 2,0\%. De hecho, estos menores costes de financiación tienen su reflejo en las TAE medias durante la pandemia. Desde marzo hasta junio, meses en los que los préstamos avalados suponían más del $60 \%$ del total del nuevo crédito, la TAE media descendió hasta el 2,1\%. Sin embargo, entre julio y octubre, periodo en el que el peso de los préstamos avalados descendió significativamente, la TAE media volvió a subir hasta el 2,6\%.

En definitiva, nuestros análisis apuntan a que los préstamos avalados han permitido que las empresas tengan acceso a préstamos con vencimientos muy superiores a los préstamos tradicionales y a costes inferiores.

\section{Impacto de los avales públicos sobre los balances bancarios}

Es necesario tener en cuenta que el volumen y las condiciones de los nuevos préstamos dependen tanto de la demanda, es decir, de las necesidades de liquidez y características de las empresas que solicitan los préstamos, como de la oferta, es decir de la situación de los bancos. Así, según la literatura, suele existir una correlación positiva entre el volumen de crédito y los niveles de solvencia de los bancos. Los programas de avales públicos sobre préstamos bancarios pueden influir positivamente en este sentido porque suponen un menor consumo de capital para los bancos, debido a que los préstamos tienen, por la parte avalada del crédito, la ponderación de riesgo correspondiente al soberano español, es decir del $0 \%$. Además, en caso de que el préstamo resultase impagado, el banco estaría cubierto en el importe del aval. De acuerdo con el estudio publicado recientemente por el Banco de España (Alves et al., 2020), la sensibilidad de los nuevos préstamos otorgados por cada banco a su ratio de capital aumentó con la irrupción de la COVID-19 y descendió tras la introducción del programa de avales. 
FIGURA 5

\section{TAE DE LOS NUEVOS CRÉDITOS CON UN NOMINAL INFERIOR A 1 MILLÓN DE EUROS}

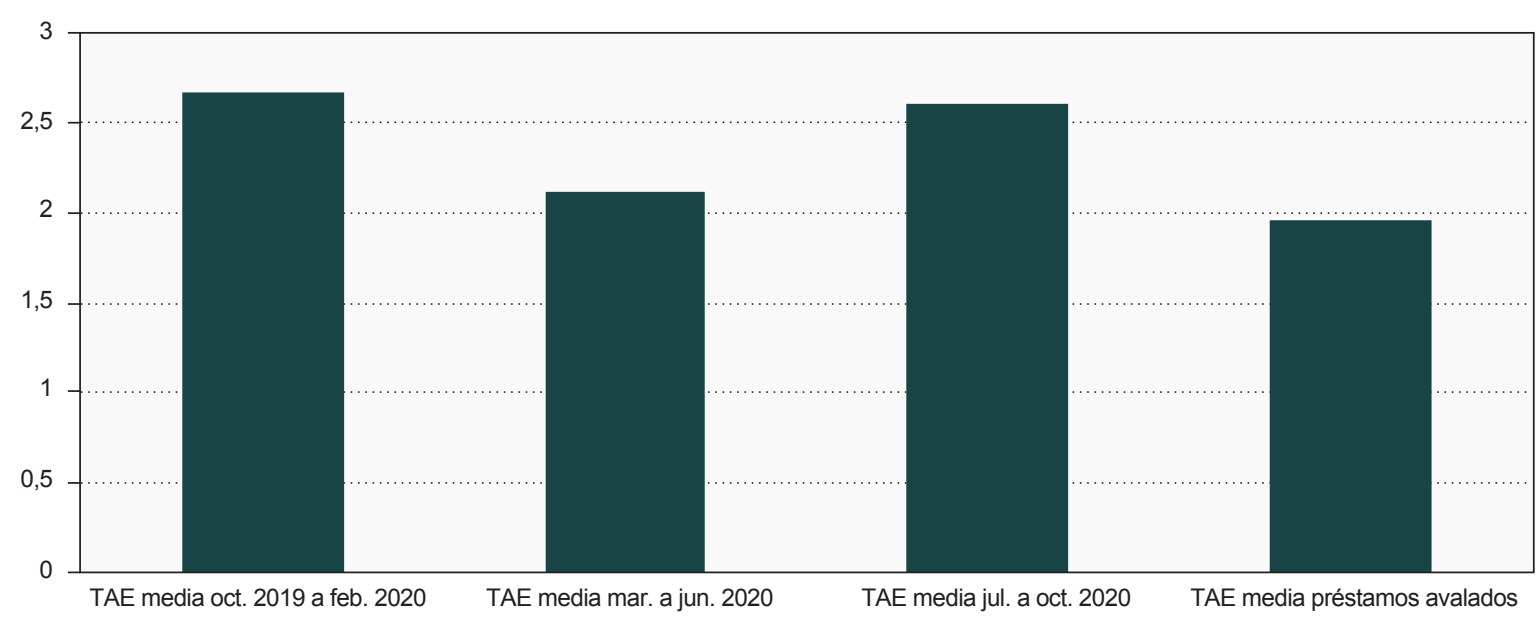

FUENTE: Banco de España e Instituto de Crédito Oficial.

Por lo tanto, podemos concluir que el programa de avales ICO ha tenido éxito a la hora de cubrir las necesidades de liquidez de las empresas y autónomos, especialmente de las que hacian frente a mayores dificultades, contribuyendo positivamente a la estabilidad financiera, evitando que se produzcan racionamientos de crédito, como ocurrió en crisis anteriores, con el consecuente impacto negativo en la actividad económica.

\section{Posibles riesgos derivados de los programas de avales públicos}

Si bien los programas de avales públicos han tenido un impacto muy positivo en el corto plazo sobre la estabilidad financiera, también hay que tener en cuenta los riesgos que puede suponer en el medio y largo plazo. El primero de estos riesgos es su posible impacto en las finanzas públicas. Contablemente, los avales se registran como pasivos contingentes para el Estado, por lo que no suponen un aumento en la deuda ni en el déficit, de hecho, en un primer momento, suponen ingresos por las primas cobradas. No obstante, en caso de que los avales llegaran a ejecutarse, ese importe sí pasaría a registrarse como déficit y deuda públicos. Otro riesgo de la línea de avales sería que provocara una asignación ineficiente de los recursos, manteniendo vivas a empresas que no son viables o rentables. En este sentido, el diseño de los avales es fundamental, en concreto, los porcentajes de cobertura limitados para alinear incentivos con los bancos y la duración limitada del programa de avales. Por lo tanto, el diseño del programa de avales español permitiría reducir estos riesgos para la estabilidad financiera.

\section{Conclusiones}

La crisis de la COVID-19 ha puesto de manifiesto la gran importancia de los vínculos entre la política fiscal y la política macroprudencial. A este respecto, extraemos cuatro conclusiones fundamentales en relación con la interrelación entre estas dos políticas: i) se suele observar una reacción inversa en una política ante cambios en el tono y orientación de la otra política; ii) la política macroprudencial produce efectos asimétricos, siendo más efectiva en la prevención que en la resolución de crisis 
financieras; iii) es necesario que ambas políticas estén coordinadas; y iv) contar con una política macroprudencial orientada a la prevención de crisis financieras y a la promoción de la estabilidad financiera conlleva ciertos costes en épocas de expansión económica que conviene asumir, dados los devastadores efectos que episodios de inestabilidad financiera pueden llegar a producir.

Entre las numerosas respuestas de política económica adoptadas frente a la COVID-19, nos hemos centrado en las líneas de avales públicos. La conclusión es inequívoca: los avales públicos han contribuido de manera notable a la estabilidad financiera de varias maneras.

En primer lugar, los avales canalizados a través del ICO han permitido garantizar el acceso al crédito en los meses de confinamiento más duro, especialmente a pymes y autónomos de sectores que se han visto más afectados por la pandemia (por ejemplo, turismo, ocio y cultura).

En segundo lugar, los préstamos avalados han permitido que las empresas tengan acceso a préstamos con vencimientos muy superiores a los préstamos tradicionales y a costes inferiores.

En tercer lugar, los programas de avales públicos permiten que la oferta de crédito de los bancos no se corte en un momento en que es clave. Ello es así porque suponen un menor consumo de capital para los bancos, debido a que los préstamos tienen, por la parte avalada del crédito, la ponderación de riesgo correspondiente al soberano español, es decir del $0 \%$. Además, en caso de que el préstamo resultase impagado, el banco estaría cubierto en el importe del aval.

Estamos convencidos de que la literatura en materia de interrelaciones entre la política fiscal y la política macroprudencial no hará sino aumentar en los próximos años. Esperamos haber contribuido, aunque sea marginalmente, a ella y continuaremos con este análisis en el futuro.

\section{Referencias bibliográficas}

Alves, P., Blanco, R., Mayordomo, S., Arrizabalaga, F., Delgado, J., Jiménez, G., Pérez Asenjo, E., Pérez Montes, C. \& Trucharte, C. (2020). Evolución reciente de la financiación y del crédito bancario al sector privado no financiero. Banco de España. Artículos analíticos. Boletín económico 4/2020. Anguren, R., Gutiérrez, L., Palomeque, E. \& Rodríguez, C. (2020). La respuesta regulatoria y supervisora frente a la crisis derivada del Covid-19. Revista de estabilidad financiera, (39), 11-45.

BCE, Banco Central Europeo (2020). Financial Stability Review.

BIS, Bank for International Settlements (2016). Towards a financial stability-oriented fiscal policy. Informe Anual 2015/2016.

Boscá, J., Ferri, J. \& Rubio, M. (2020, December). Fiscal and macroprudential policies in a monetary union. Preliminary version.

Bruegel datasets (2020). The fiscal response to the economic fallout from the coronavirus.

Cuadro-Sáez, L., López-Vicente, F., Párraga, S. \& Viani, F. (2020). Medidas de política fiscal en respuesta a la crisis sanitaria en las principales economías del Área del Euro, Estados Unidos y Reino Unido. Banco de España, Documentos Ocasionales n 2019.

Dumičić, M. (2019). Linkages Between Fiscal Policy and Financial (In)Stability. Journal of Central Banking Theory and Practice, Central bank of Montenegro, 8(1), 97-109.

EBA, European Banking Authority (2020). First evidence on the use of moratoria and public guarantees in the EU banking sector.

ESRB, European Systemic Risk Board (2015). ESRB report on the regulatory treatment of sovereign exposures.

Falagiarda, M., Prapiestis, A. \& Rancoita, E. (2020). Public loan guarantees and bank lending in the COVID-19 period. ECB, Economic Bulletin, 6.

Houben, A. \& Kakes, J. (2013). Financial imbalances and macroprudential policy in a currency union. DNB Occasional Studies 1105. Netherlands Central Bank, Research Department.

IMF, International Monetary Found, FSB, Financial Stability Board, \& BIS, Bank For International Settlements (2016). Elements of Effective Macroprudential Policies.

Laeven, L. \& Valencia, F. (2012). Systemic Banking Crises Database. IMF Working Paper 12/163.

Real Decreto-ley 8/2020, de 17 de marzo de medidas urgentes extraordinarias para hacer frente al impacto económico y social del COVID-19. Boletín Oficial del Estado, núm. 73, de 18 de marzo de 2020, pp. 25853 a 25898.

Real Decreto-ley 25/2020, de 3 de julio, de medidas urgentes para apoyar la reactivación económica y el empleo. Boletín Oficial del Estado, núm. 185, de 6 de julio de 2020, pp. 47684 a 47742 . https://www.boe.es/boe/dias/2020/07/06/ pdfs/BOE-A-2020-7311.pdf

Reis, R. (2020). The fiscal footprint of macroprudential policy. Deutsche Bundesbank. Discussion Papers 31/2020. https:// personal.Ise.ac.uk/reisr/papers/20-macroprufiscal.pdf 